\title{
Energy management strategy for fuel cell-supercapacitor hybrid vehicles based on prediction of energy demand
}

\author{
Mauro G. Carignano ${ }^{a, *}$, Ramon Costa-Castellób ${ }^{b}$ Vicente Roda $^{c}$, Norberto M. Nigro ${ }^{\text {d }}$, Sergio \\ Junco $^{\mathrm{e}}$, Diego Feroldi ${ }^{\mathrm{f}}$ \\ ${ }^{a}$ Escuela de Ingeniería Mecánica, CONICET-FCEIA-UNR, Beruti 2109, S2000FFI, Rosario, Argentina. \\ mauroc@fceia.unr.edu.ar \\ ${ }^{b}$ Departament d'Enginyeria de Sistemes, Automàtica i Informàtica Industrial, UPC, C/Pau Gargallo 5, \\ 08028, Barcelona, Spain.ramon.costa@upc.edu \\ ${ }^{c}$ Institut de Robòtica i Informàtica Industrial, CSIC-UPC, C/Llorens i Artigas 4-6, 08028, Barcelona, Spain. \\ vroda@iri.upc.edu \\ ${ }^{d}$ Centro de Investigación de Métodos Computacionales, CIMEC-CONICET-UNL, Colectora Ruta Nac. N 168 \\ km.0, Pje El Pozo, Santa Fe, Argentina.norberto.nigro@cimec.santafe-conicet.gov.ar \\ ${ }^{e}$ LAC, Laboratorio de Automatización y Control, FCEIA-UNR, Riobamba 245 bis, S2000EKE, Rosario, \\ Argentina.sjunco@fceia.unr.edu.ar \\ ${ }^{f}$ Centro Internacional Franco Argentino de Ciencias de la Información y de Sistemas, CIFASIS-CONICET, \\ Ocampo y Esmeralda, S2000EZP, Rosario, Argentina.feroldi@cifasis-conicet.gov.ar
}

\begin{abstract}
Offering high efficiency and producing zero emissions Fuel Cells (FCs) represent an excellent alternative to internal combustion engines for powering vehicles to alleviate the growing pollution in urban environments. Due to inherent limitations of FCs which lead to slow transient response, FC-based vehicles incorporate an energy storage system to cover the fast power variations. This paper considers a FC/supercapacitor platform that configures a hard constrained powertrain providing an adverse scenario for the energy management strategy (EMS) in terms of fuel economy and drivability. Focusing on palliating this problem, this paper presents a novel EMS based on the estimation of short-term future energy demand and aiming at maintaining the state of energy of the supercapacitor between two limits, which are computed online. Such limits are designed to prevent active constraint situations of both FC and supercapacitor, avoiding the use of friction brakes and situations of non-power compliance in a short future horizon. Simulation and experimentation in a case study corresponding to a hybrid electric bus show improvements on hydrogen consumption and power compliance compared to the widely reported Equivalent Consumption Minimization Strategy. Also, the comparison with the optimal strategy via Dynamic Programming shows a room for improvement to the real-time strategies.
\end{abstract}

Keywords: Fuel cell-supercapacitor hybrid vehicle, State constraint, Energy management

\footnotetext{
${ }^{*}$ Corresponding author. Email address: mauroc@fceia.unr.edu.ar, tel:+543414808536, fax:+543414802654, Beruti 2109, S2000FFI, Rosario, Argentina.
} 
strategy, Fuel economy, Drivability 


\section{Introduction}

Fuel Cell Hybrid Vehicles (FCHV) represent a solution of increasing interest for car manufacturers. Some examples are Hyundai (TUCSON), General Motors (Chevrolet Equinox), Honda (FCX-V4 y FCX Clarity), Toyota (Toyota FCHV) and Volkswagen (Passat Lingyu). Nevertheless, some matters associated to hydrogen $\left(\mathrm{H}_{2}\right)$ production; distribution and storage; and fuel cell cost and lifetime, must be improved to make this technology more profitable and affordable [1]. . Fuel Cells (FCs) offer two main advantages compared to the internal combustion engines: higher efficiency and zero emissions. However, despite these advantages, FCs present some limitations associated with its slow transient response, which must be taken into account to avoid premature aging $[2,3,4]$. Taking into account such restriction, FCHVs incorporate an energy storage system to cover the fast power variations. Additionally, this energy storage system allows to recover energy from braking. In most cases, a battery is adopted for such purpose. Despite the advances on this technology, electrochemical batteries still offer a relative short lifetime limited to thousands of cycles $[5,6]$. To solve this drawback, FCHVs incorporate a supercapacitor (SC) to replace the battery or in combination with that [7]. In contrast to batteries, SCs offer hundreds of thousands of duty cycles and a higher specific power $[8,9]$, with the disadvantages of having lower specific energy and higher cost per unit of energy stored.

From the point of view of the energy management strategy (EMS), FCHVs with SC represent and adverse scenario due to the existence of active state-dependent constraints. Such constraints affect sensitively both the $\mathrm{H}_{2}$ consumption and the fulfillment of power demand. A review of EMS for FCHV presented in [1] indicates that the Equivalent Consumption Minimization Strategy (ECMS) is the most outstanding strategy. There are a large number of works reported in the literature about this strategy but most of them dealing with Engine/Battery hybrid vehicles. In the case of FCHV with SC, the formulation differs slightly from the previous one. Rodatz et al. [10] presents a complete description of the ECMS and the implementation, including experimental validation, in a FCHV with SC. The performance obtained in terms of $\mathrm{H}_{2}$ consumption shows results comparable to, but not better than, the map-based control strategy presented in [11]. Although ECMS provides a close-to-optimal solution in a wide range of hybrid platforms, especially in the case of using internal combustion engine and battery $[12,13]$, the differences with the optimal solution increases in case of a system with active state constraints. A comparison presented in [14] shows differences higher than $10 \%$ between the ECMS and the optimal offline strategy. Pérez et al. [15] uses Pontryagin's minimum 
principle to obtain offline the trajectory of the adjoint state with the purpose of improving the performance of the ECMS in the cases of active state constraints.

In contrast to optimization approaches, rule-based strategies are also reported in the literature. This approach offers in general an acceptable performance and lower computational burden, which become more suitable for real time application [16, 17]. Most rule-based or mapped strategies only use the state of charge of supercapacitors and the power demand as inputs. Feroldi et al. [18] presents a rule-based strategy based on a FC map efficiency. The results obtained show a difference of around $6 \%$ on $\mathrm{H}_{2}$ consumption compared to the optimal offline strategy. Despite the good performance obtained, the size of supercapacitor bank adopted in [18] seems to be large enough so that no active state constraints appear, which provides favorable conditions for the EMS.

In this work, a new EMS for a FCHV with SC based on energy estimations is presented. The strategy is specially designed for platforms in which state-dependent constraints get often active in operation. It uses information of the current states of the vehicle such as vehicle speed, SC state of energy and FC power flow. The case study concerns a hybrid electric bus operated under urban driving conditions. First, the performance of the proposed strategy is evaluated by simulation using a quasistatic model of the powertrain, and the results are compared to those of ECMS and to the optimal offline strategy obtained through Dynamic Programming. Simulation results include a sensitivity analysis against changes in the driving condition and the mass of the vehicle. Finally, an experimental validation is carried out in a hybrid power station. The rest of the paper is organized as follows: in Section 2, the model of the FCHV is presented; Section 3 describes the novel strategy; in Section 4, the case study is described and the results obtained by simulations are shown; in Section 5, the experimental validation is presented; and finally the conclusions and a prospective are drawn in Section 6. 


\section{Vehicle Model}

The configuration of the FCHV adopted in this work is shown in Fig. 1. As can be observed, the power at wheels is provided by the Electric Machine (EM) through the differential. The EM can also work as a generator to recover energy from braking, and it is connected to the direct current bus (DC-BUS) through a bidirectional converter. Finally, the FC delivers power through the Boost converter to the direct current bus (DC-BUS), while the SC delivers or receives power via the Buck/Boost converter.

The model of the powertrain used to evaluate the $\mathrm{H}_{2}$ consumption and the power compliance focuses on the efficiency and the constraints, neglecting most of the dynamics. Some comparison reported in the literature between quasistatic model against high order model [12] or real system [19] show the closeness of the results. In the following all the models are formulated in discrete time.

\subsection{Supercapacitor model}

An analytic expression to model the SC can be deduced from the equivalent circuit composed of a capacitor and a resistor connected in series.

The SC current can be expressed as a function of the power demanded $P_{S C}$,

$$
I_{S C}(k)=\frac{U_{S C, o c}(k)-\left(U_{S C, o c}^{2}(k)-4 P_{S C}(k) R_{S C}\right)^{0.5}}{2 R_{S C}} .
$$

where $R_{S C}$ is the internal resistance, $U_{S C, o c}(k)=Q_{S C}(k) / C_{S C}$ is the open-circuit voltage, and $Q_{S C}(k)$ and $C_{S C}$ are the charge and the capacity of the SC, respectively. As the proposed EMS is based on energy estimations, it is appropriate to introduce the energy as a variable. Hence, the energy stored $\left(E_{S C}\right)$ and the nominal energy $\left(E_{S C, 0}\right)$ of the SC are introduced as follows:

$$
E_{S C}(k)=0.5 C_{S C} U_{S C, o c}^{2}(k), \quad E_{S C, 0}=0.5 C_{S C} U_{S C, 0}^{2}
$$

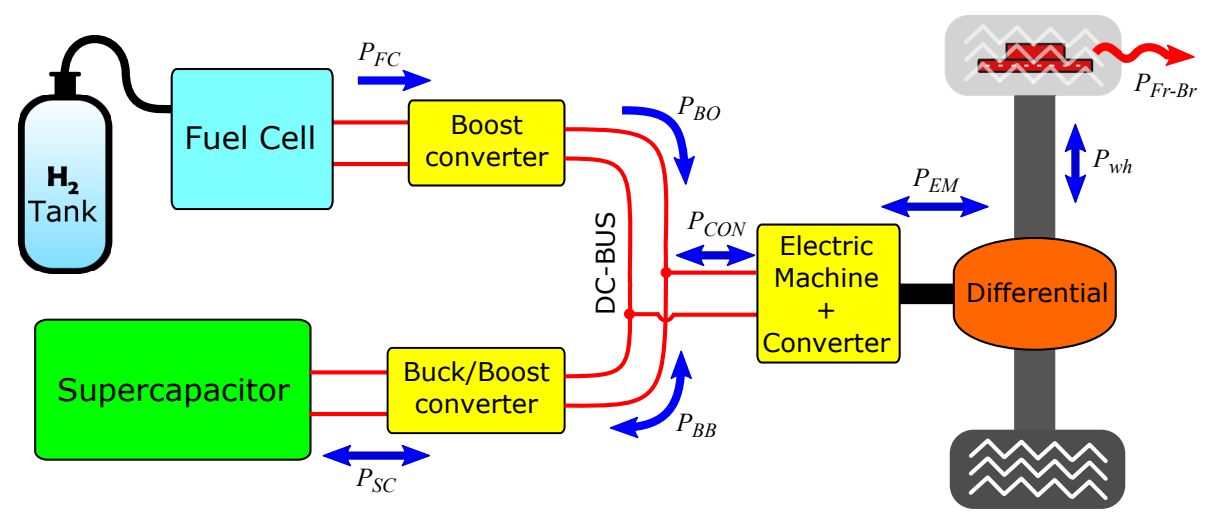

Figure 1: FCHV configuration. 
where $U_{S C, 0}$ is the nominal voltage. Notice that here "nominal" means fully charged. Now, the state of energy $(S O E)$ is the relation between the energy stored and the nominal energy of SC, and its dynamics can be expressed as follows,

$$
S O E(k+1)=S O E(k)-\frac{U_{S C, o c}(k) I_{S C}(k) t_{s}}{E_{S C, 0}},
$$

where $t_{s}$ is the time discretization interval. With this definition, the current in the SC is considered positive for discharging.

Concerning the constraints, fixed lower and upper limits of $S O E$ are considered, and the current is also limited, i.e.:

$$
\begin{gathered}
S O E_{\min } \leq S O E(k) \leq S O E_{\max } \\
-I_{S C}^{\max } \leq I_{S C}(k) \leq I_{S C}^{\max }
\end{gathered}
$$

Notice that (4) is a state constraint, and (5) is a state-dependent constraint, due to (1)-(3).

\subsection{Fuel cell model}

Hydrogen FCs are used to generate electricity from an electrochemical reaction between oxygen and $\mathrm{H}_{2}$. For the purposes of this work, the FC is reduced to a quasistatic model, including its constraints and efficiency map. Assuming that the response time of the system is noticeably lower than the sampling time, it can be considered that the power delivered by the $\mathrm{FC}$ in the each interval of time is exactly the power reference $P_{F C}(k)$ received as input in the low level controller.

On the other hand, the power gradient in the $\mathrm{FC}$ is $\Delta P_{F C}(k)=\left(P_{F C}(k)-P_{F C}(k-1)\right) / t_{s}$. Then, the control input is limited to the following physical constraints:

$$
\begin{gathered}
0 \leq P_{F C}(k) \leq P_{F C}^{\max }, \\
\Delta P_{F C}^{\min } \leq \Delta P_{F C}(k) \leq \Delta P_{F C}^{\max },
\end{gathered}
$$

where $P_{F C}^{\max }$ is the maximum power of the $\mathrm{FC}$, and $\Delta P_{F C}^{\min }$ and $\Delta P_{F C}^{\max }$ are the maximum and minimum allowed power gradients. Currently, it is not entirely clear how to accurately establish the power rate limits to assure non-premature ageing of FCs. Quantifying degradation in FCs is a complex task because the degradation rate strongly depends on the internal conditions $[20,21]$. Although some authors do not consider power rate constraints in the fuel cell [22, $23,24,25]$, values between $2 \%$ and $20 \%$ of its maximum power per second are usually adopted $[26,27,10,18,28,29,14,30]$. In this work, a maximum of $10 \%$ of the maximum power of the FC per second for rising and falling is assumed. Notice that the constraint given by (7) 
depends on the previous and the current power values. An option to deal with such a restriction is to consider the power in the $\mathrm{FC}$ as a state variable, i.e. $x_{F C}(k+1)=P_{F C}(k)$, and then, the constraint (7) is state-dependent. This restriction, in general, imposes hard constraints for the EMS, affecting noticeably the vehicle performance.

Finally, the efficiency of the FC is defined as the relation between the electric power delivered and the power consumed from $\mathrm{H}_{2}, \eta_{F C}=P_{F C} /\left(\dot{m}_{H_{2}} L H V_{H_{2}}\right)$, where $\dot{m}_{H_{2}}$ and $L H V_{H_{2}}$ are the mass flow and the lower heating value of $\mathrm{H}_{2}$, respectively. The maps of consumption and efficiency according to the power are given by the manufacturer. In this case, the data of a Proton Exchange Membrane FC given by Nexa ${ }^{\mathrm{TM}}$ [31] was used. The maps take into account the power required for the auxiliary components. Using this information, it is possible to compute the instantaneous consumption of $\mathrm{H}_{2}$ via interpolation.

\subsection{FCHV model}

From Fig. 1, the following set of algebraic equations can be deduced:

$$
\begin{aligned}
P_{B O}(k) & =P_{F C}(k) \eta_{B O}, \\
P_{S C}(k) & =P_{B B}(k) \eta_{B B}^{-\operatorname{sign}\left(P_{B B}(k)\right)}, \\
P_{B B}(k)+P_{B O}(k) & =P_{E M}(k) \eta_{E M}^{-\operatorname{sign}\left(P_{E M}(k)\right)}, \\
P_{E M}(k) & =P_{w h}(k) \eta_{D F}^{-\operatorname{sign}\left(P_{w h}(k)\right)},
\end{aligned}
$$

where $\eta_{B O}, \eta_{B B}, \eta_{E M}$ and $\eta_{D F}$ are the efficiencies of Boost converter, Buck/Boost converter, EM and differential, respectively. The function "sign" allows to shift the efficiency according to the direction of power flow. Then, the relation between power and torque in the EM is:

$$
T_{E M}(k) \omega_{E M}(k)-P_{E M}(k)=0, \quad \omega_{E M}(k)=\frac{i_{D F} v(k)}{R_{w h}},
$$

where $\omega_{E M}$ and $v$ are the speed of the EM and the vehicle respectively, $i_{D F}$ is the transmission ratio of the differential, and $R_{w h}$ is the wheel radius. By analyzing the number of unknown variables and the number of equations in (8)-(12), and assuming that $P_{w h}(k)$ and the $v(k)$ are known, it is verified that the propulsion system has one degree of freedom. In this case, $P_{F C}(k)$ is chosen as control input, which will be computed by the EMS.

On the other hand, the power required at the wheels depends on the desired speed profile, which is usually given by a driving cycle. In this work, the power at the wheels is determined by the inverse model of the vehicle dynamics, that considers inertial forces, rolling resistance and aerodynamic drag. From the current speed of vehicle $v(k)$, and with the speed required at 
next step $v_{r e q}(k+1)$, the power required at the wheels $\left(P_{w h}^{r e q}\right)$ is computed using the following set of equations:

$$
\begin{aligned}
a(k) & =\left(v_{\text {req }}(k+1)-v(k)\right) t_{s}^{-1}, \\
F_{\text {iner }}(k) & =m a(k), \\
F_{\text {aero }}(k) & =0.5 A_{f} C_{x} \rho_{\text {air }} v(k)^{2}, \\
F_{\text {roll }}(k) & =m g\left(r_{0}+r_{1} v(k)\right), \\
F_{w h}(k) & =F_{\text {aero }}(k)+F_{\text {roll }}(k)+F_{\text {iner }}(k), \\
P_{w h}^{r e q}(k) & =F_{w h}(k) v(k),
\end{aligned}
$$

where $a$ is the linear acceleration; $m$ is the total mass of the vehicle; $A_{f}, C_{x}$ and $\rho$ are frontal area, drag coefficient and air density respectively; $r_{0}$ and $r_{1}$ are rolling resistance coefficients; and $g$ is the acceleration of gravity.

It is necessary to know the power demanded at the wheels to compute the EMS. Before using $P_{w h}^{r e q}$, it is bounded according to the power available from the propulsion system. The maximum (and minimum) power available at each time depends on the physical limitations of the components. Table 1 summarizes the constraints of the propulsion system. Taking into account these constraints, it is possible to compute at each time the maximum and minimum power available at wheel, namely $P_{w h}^{\max }$ and $P_{w h}^{\min }$. It is worth to notice that these values depend on the vehicle speed, and on the state variables $x_{F C}$ and $S O E$. The power available at the

Table 1: Constraints in the propulsion system.

\begin{tabular}{lcc}
\hline Variable & min. & $\max$. \\
\hline EM Torque, $T_{E M}$ & $-T_{E M}^{\max }$ & $T_{E M}^{\max }$ \\
EM Power, $P_{E M}$ & $-P_{E M}^{\max }$ & $P_{E M}^{\max }$ \\
FC power, $P_{F C}$ & 0 & $P_{F C}^{\max }$ \\
FC gradient, $\Delta P_{F C}$ & $\Delta P_{F C}^{\min }$ & $\Delta P_{F C}^{\max }$ \\
Buck/Boost Power, $P_{B B}$ & $-P_{B B}^{\max }$ & $P_{B B}^{\max }$ \\
SC current, $I_{S C}$ & $-I_{S C}^{\max }$ & $I_{S C}^{\max }$ \\
SC energy, $S O E$ & $S O E_{\min }$ & $S O E_{\max }$ \\
\hline
\end{tabular}

wheels is directly related to the drivability (speed compliance) and to the global efficiency. It means that, in case of propulsion, when $P_{w h}^{r e q}$ is higher than $P_{w h}^{\max }$, the future speed achieved will be lower than the speed required. On the contrary, in case of regenerative braking, when $P_{w h}^{m i n}$ is higher than the power required, the friction brakes must be employed. Finally, the 
power required at the wheels given by (13) is bounded as follows:

$$
P_{w h}(k)=\max \left\{\min \left\{P_{w h}^{r e q}(k) ; P_{w h}^{\max }(k)\right\} ; P_{w h}^{\min }(k)\right\},
$$

and the power dissipated on the friction brakes results:

$$
P_{F r-B r}(k)= \begin{cases}0, & \text { if } P_{w h}^{r e q}(k) \geq 0, \\ P_{w h}^{\min }(k)-P_{w h}^{r e q}(k), & \text { if } P_{w h}^{r e q}(k)<0 .\end{cases}
$$

Figure 2 shows a schematic representation of the causal model used to perform the simulations. Notice that, if the power required is lower than the power available, a new value of future speed is computed by using the longitudinal vehicle model. The block named "Power balance" in Fig. 2 refers to the set of equations (8)-(11).

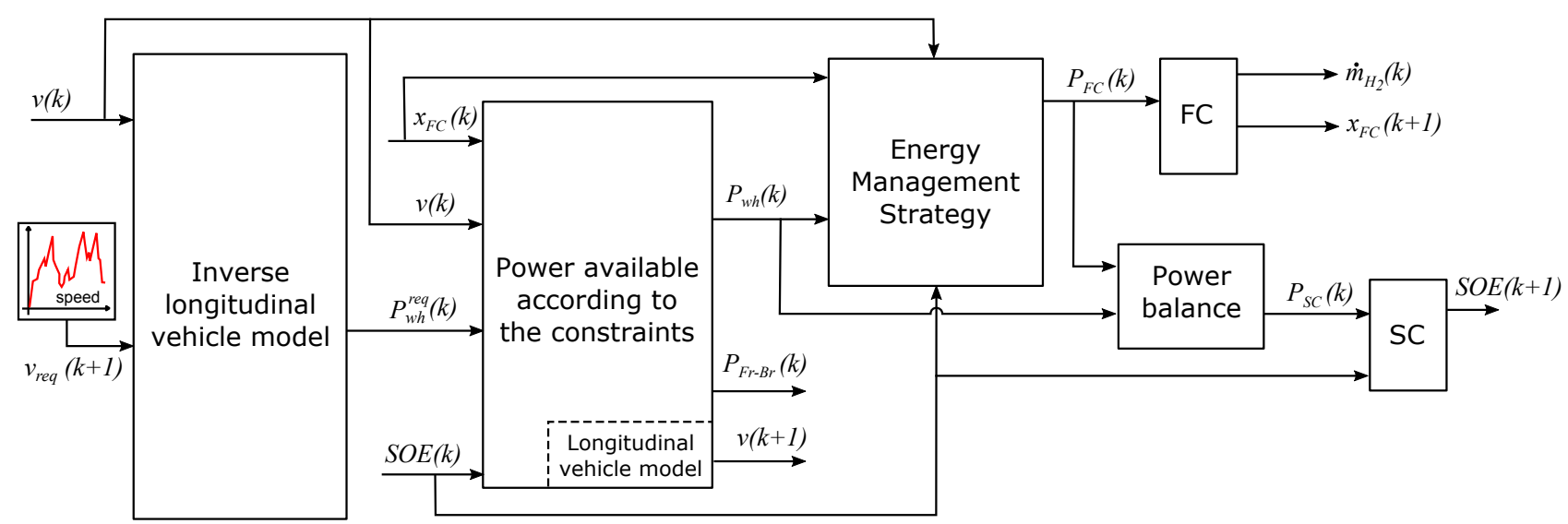

Figure 2: Schematic representation of the model to perform the simulations. 


\section{Energy-based Estimation Strategy}

The EMS proposed in this work, named hereafter Energy-Based Estimation Strategy (EBES), has three goals: i) to provide at any time the power required to propel the vehicle; ii) to recover as much energy as possible from braking; and iii) to operate the fuel cell at maximum efficiency. Figure 3 shows the flowchart of the strategy. In the first step, two $S O E$ limits are computed using the current speed and the state of the FC. Then, by comparing such values with the current $S O E$, and taking into account the power demanded at wheel, the FC power reference $\left(u_{F C}\right)$ is computed. Finally, the power value for the FC is bounded according to the constraints of the propulsion system. The procedure to compute the $S O E$ limits is described below.

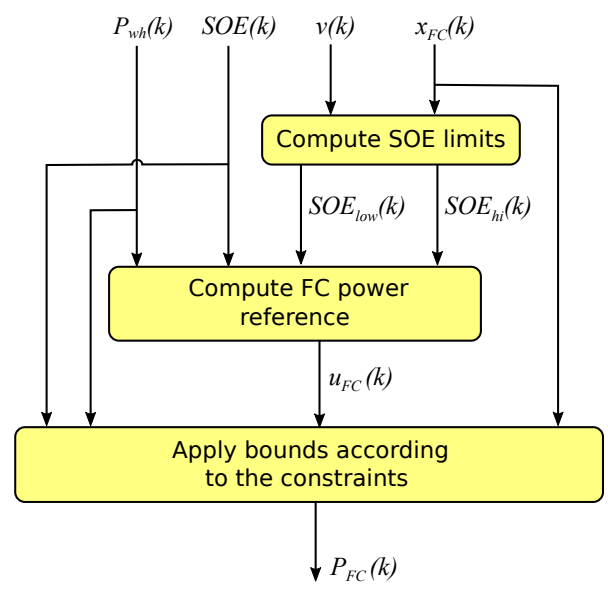

Figure 3: Flowchart of the Energy-based Estimation Strategy.

\subsection{Determination of the supercapacitor SOE limits}

This stage is the core of the strategy, in which, an upper and a lower limit of $S O E$, namely $S O E_{h i}$ and $S O E_{l o w}$, are found. In contrast to previous published strategies (for example in [18]), in this work such limits are not fixed, but they are adapted during runtime according to the vehicle speed and FC power state. Specifically, these limits are computed so that if the current $S O E$ is between $S O E_{h i}$ and $S O E_{l o w}$, the propulsion system is able to accelerate from the current speed up to a predefined maximum speed; and also it is able to store overall energy produced by both the regenerative braking and FC from the current speed until the vehicle stops. Accordingly, the first step to know such limits is to estimate the energy required for the vehicle in a short future period of time to change its speed.

\subsubsection{Trip energy estimation}

Hereafter the term "trip" will be used to refer to hypothetical short time displacement in which the vehicle accelerates o decelerates uniformly from a given current speed until a certain 

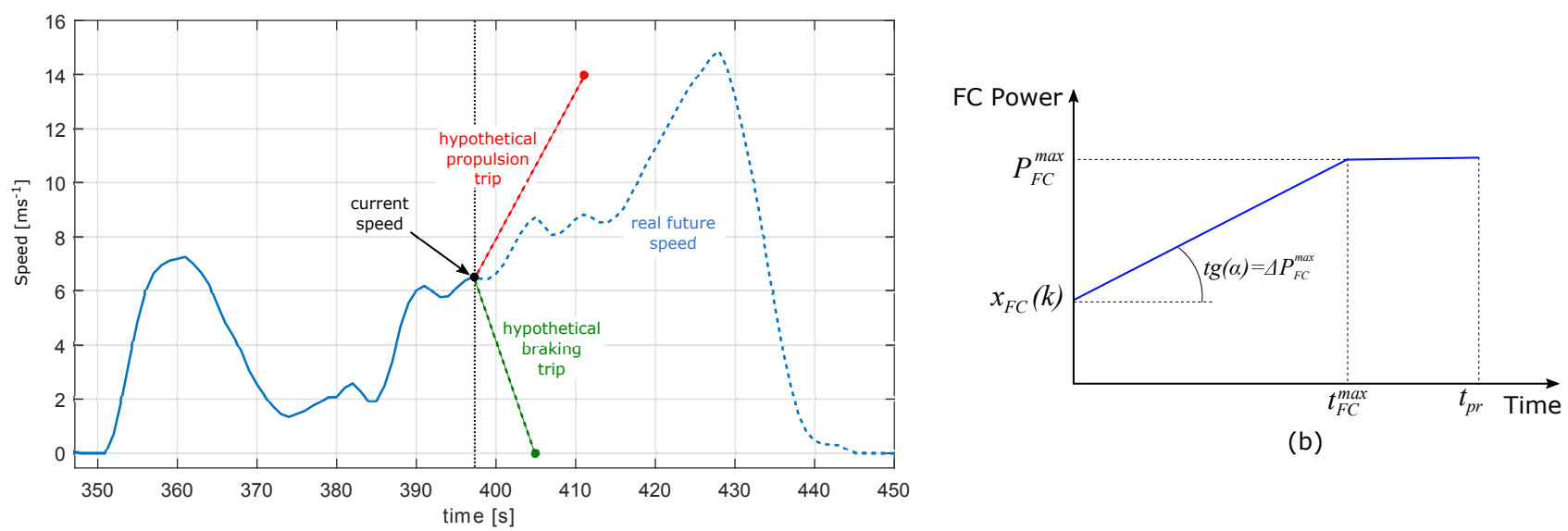

(b)

(a)

Figure 4: (a) Hypothetical future trips from the current speed, (b) Evolution of FC power from current state to maximum power.

future speed (see Fig. 4-(a)).

An estimation of the energy required during a trip from an initial speed $v_{0}$ to a final speed $v_{f}$ can be done considering the variation of kinetic energy. However, such approximation neglects the dissipation effects produced by aerodynamics and rolling resistances. A more accurate estimation is obtained taking into account such effects. Then, the total energy required (at the wheels) is the sum of the three terms:

$$
E_{\text {trip }}=E_{\text {kin }}+E_{\text {aero }}+E_{\text {roll }}
$$

where $E_{\text {kin }}, E_{\text {aero }}$ and $E_{\text {roll }}$ are the kinetic energy variation, the energy dissipated by aerodynamics effect, and the energy dissipated by rolling resistance respectively. Notice that $E_{\text {aero }}$ and $E_{\text {roll }}$ are always positive, while $E_{\text {kin }}$ depends on whether it is a propulsion trip (positive) or a braking trip (negative), and therefore $E_{\text {trip }}$ might be positive or negative. The kinetic energy variation from $v_{0}$ to $v_{f}$ is

$$
E_{k i n}=0.5 m\left(v_{f}^{2}-v_{0}^{2}\right)
$$

Then, the energy dissipated by aerodynamics effect during a trip is

$$
E_{\text {aero }}(t)=\int_{0}^{t} C_{\text {aero }} v^{3}(\tau) d \tau
$$

where $C_{\text {aero }}=0.5 A_{f} C_{x} \rho_{\text {air }}$. From $v_{0}$, and assuming a constant acceleration $a$ during the trip, (18) results:

$$
E_{\text {aero }}(t)=\int_{0}^{t} C_{\text {aero }}\left(v_{0}+a \tau\right)^{3} d \tau
$$

and solving the definite integral leads to:

$$
E_{\text {aero }}(t)=C_{\text {aero }}\left(\frac{a^{3} t^{4}}{4}+a^{2} t^{3} v_{0}+\frac{3 a t^{2} v_{0}^{2}}{2}+t v_{0}^{3}\right)
$$


Then, assuming a final speed $v_{f}$, the time required to reach such speed is $t=\left(v_{f}-v_{0}\right) / a$. Replacing in (20) and by algebraic simplification, the expression to compute the energy dissipated by aerodynamics results:

$$
E_{\text {aero }}=\frac{C_{a e r o}}{4 a}\left(v_{f}^{4}-v_{0}^{4}\right)
$$

For the rolling resistance, a similar procedure is used. From an initial speed and constant acceleration, the energy dissipated results:

$$
\begin{aligned}
E_{\text {roll }}(t) & =\int_{0}^{t} m g\left(r_{0}+r_{1} v(\tau)\right) v(\tau) d \tau \\
& =m g \int_{0}^{t} r_{0}\left(v_{0}+a \tau\right)+r_{1}\left(v_{0}+a \tau\right)^{2} d \tau
\end{aligned}
$$

and solving the definite integral leads to:

$$
E_{\text {roll }}(t)=m g\left(\left(r_{0} v_{0}+r_{1} v_{0}^{2}\right) t+\frac{\left(r_{0}+2 v_{0} r_{1}\right) a \cdot t^{2}}{2}+\frac{r_{1} a^{2} t^{3}}{3}\right),
$$

and, with $t=\left(v_{f}-v_{0}\right) / a$, the expression to compute the energy dissipated by rolling resistance results:

$$
E_{\text {roll }}=\frac{m g}{a}\left(\frac{r_{1}\left(v_{f}^{3}-v_{0}^{3}\right)}{3}+\frac{r_{0}\left(v_{f}^{2}-v_{0}^{2}\right)}{2}\right) .
$$

According to (21) and (24), it is easy to verify that the effect of the aerodynamic and rolling resistances in the trip energy increases as the acceleration (in absolute value) decreases.

Summarizing, from (17), (21) and (24) it is possible to compute, analytically, an estimation of the energy required in a trip, by using the initial and final speed, the acceleration and the vehicle parameters.

\subsubsection{Lower state of energy}

The lower state of energy, namely $S O E_{\text {low }}$, is computed so that if the current $S O E$ is higher than $S O E_{\text {low }}$, the propulsion system is able to provide the energy required to go from the current speed up to a maximum predefined speed $\left(v_{\max }\right)$. During a propulsion trip, the energy required at the wheels is computed from (16), with $v_{0}=v(k), v_{f}=v_{\max }$ and $a=a_{p r}$, where $a_{p r}$ and $v_{\max }$ are adjustable parameters. Then, using the efficiencies of the components, the energy required from DC-BUS results:

$$
E_{p r}(k)=\frac{E_{t r i p}(k)}{\eta_{D F} \eta_{E M}} .
$$

This energy drawn from the DC-BUS must be supplied by the FC and the SC, which leads to:

$$
E_{S C}(k) \eta_{S C} \eta_{B B}+E_{F C}^{p r}(k) \eta_{B O} \geq E_{p r}(k)
$$


where $E_{S C}$ is the energy available in the SC, $\eta_{S C}$ is the average efficiency of SC, and $E_{F C}^{p r}$ is the maximum energy that the FC is able to provide during this trip. The latter is computed assuming that the FC rises up to its maximum power from its current state as fast as possible. Therefore, $E_{F C}^{p r}$ can be computed as the area under the curve showed in the Fig. 4-(b), which leads to:

$$
E_{F C}^{p r}(k)= \begin{cases}t_{F C}^{\max }(k)\left(\frac{P_{F C}^{\max }+x_{F C}(k)}{2}\right)+\left(t_{p r}(k)-t_{F C}^{\max }(k)\right) P_{F C}^{\max } & \text { if } t_{p r}(k) \geq t_{F C}^{\max }(k), \\ t_{p r}(k)\left(\frac{P_{F C}^{\max }(k)+x_{F C}(k)}{2}\right) & \text { if } t_{p r}(k)<t_{F C}^{\max }(k) .\end{cases}
$$

Here, $t_{F C}^{\max }$ is the time the FC takes to reach the maximum power, and $t_{p r}$ is the time the trip takes from $v(k)$ up to $v_{\max }$ with constant acceleration $a_{p r}$ :

$$
t_{F C}^{\max }(k)=\frac{P_{F C}^{\max }-x_{F C}(k)}{\Delta P_{F C}^{\max }} ; \quad t_{p r}(k)=\frac{v_{\max }-v(k)}{a_{p r}} .
$$

Although in Fig. $4 t_{p r}$ is higher than $t_{F C}^{m a x}$, the opposite situation is also possible, which corresponds to the second case of (27). Now, from (26) and with the definition of SOE, it follows that:

$$
S O E(k) \geq\left(\frac{E_{p r}(k)-E_{F C}^{p r}(k) \eta_{B O}}{\eta_{S C} \eta_{B B} E_{S C, 0}}\right) .
$$

Notice that by fulfilling this expression, the propulsion system has enough energy to propel the vehicle from the current speed until $v_{\max }$ with the constant acceleration $a_{p r}$. Then, taking into account the minimum $S O E$ allowed in the $\mathrm{SC}$, the lower $S O E$ due to energy is defined as:

$$
S O E_{l o w, E}(k)=\left(\frac{E_{p r}(k)-E_{F C}^{p r}(k) \eta_{B O}}{\eta_{S C} \eta_{B B} E_{S C, 0}}\right)+S O E_{m i n} .
$$

So far, the condition $\operatorname{SOE}(k) \geq S O E_{\text {low, }}(k)$ assures that the vehicle has the required energy for the trip, i.e. the constraint associated with $S O E$ will not be activated. In addition, the constraint associated with the maximum SC current is potentially activated, specially when $S O E$ is low, because the voltage falls and the current rises noticeably. To avoid that, a lower $S O E$ by current, namely $S O E_{l o w, I}$, must be found. It is defined in such a way that when $S O E(k)>S O E_{\text {low }, I}$, a power flow in the Buck/Boost equal to $P_{B B}^{\max }$ produces a current on the $\mathrm{SC}$ side lower than $I_{S C}^{\max }$. From the SC model, it leads to:

$$
S O E(k) \geq\left(\frac{P_{B B}^{\max }}{\eta_{B B} I_{S C}^{\max }}+R_{S C} I_{S C}^{\max }\right)^{2} \frac{C_{S C}}{2 E_{S C, 0}}
$$

where the right-hand term is the lower limit by current:

$$
S O E_{l o w, I}=\left(\frac{\eta_{B B}^{-1} P_{B B}^{\max }}{I_{S C}^{\max }}+R_{S C} I_{S C}^{\max }\right)^{2} \frac{C_{S C}}{2 E_{S C, 0}} .
$$


Notice that, unlike (30), this expression does not depend on $k$. Finally, the lower SOE limit for the strategy is computed as follows:

$$
S O E_{\text {low }}(k)=\max \left\{S O E_{\text {low }, E}(k) ; S O E_{\text {low }, I}\right\} .
$$

\subsubsection{Higher state of energy}

The higher state of energy, namely $S O E_{h i}$, is computed so that if the current $S O E$ is lower than $S O E_{h i}$, the $\mathrm{SC}$ is able to recover all the energy from the wheels and from the FC during a braking trip from the current speed until the vehicle stops. This condition can be expressed as follows:

$$
\frac{E_{S C, 0}-E_{S C}(k)}{\eta_{S C}} \geq\left(E_{b r}(k)+E_{F C}^{b r}(k) \eta_{B O}\right) \eta_{B B},
$$

where the left hand side represents the maximum energy that can be stored in the SC from the current $S O E ; E_{b r}$ is the energy delivered to the DC-BUS from the regenerative braking; and $E_{F C}^{b r}$ is the minimum energy delivered by the FC during this trip. Now, solving for $E_{S C}$ from (34), and expressing $E_{S C}$ in term of $S O E$, (34) leads to:

$$
S O E(k) \leq 1-\frac{\left(E_{b r}(k)+E_{F C}^{b r}(k) \eta_{B O}\right) \eta_{B B} \eta_{S C}}{E_{S C, 0}} .
$$

In this expression, $E_{b r}(k)$ is computed from (16), with $v_{0}=v(k), v_{f}=0$ and $a=a_{b r}$, where $a_{b r}$ is an adjustable parameter. Then, using the efficiencies of the components, $E_{b r}(k)$ results:

$$
E_{b r}(k)=-E_{t r i p}(k) \eta_{D F} \eta_{E M}
$$

Then, to compute $E_{F C}^{b r}$, it is assumed that from the current power state, the FC falls down to zero as fast as possible, resulting in:

$$
E_{F C}^{b r}(k)=\frac{x_{F C}^{2}(k)}{-2 \Delta P_{F C}^{\min }}
$$

Notice that by fulfilling (35), the SC is able to store all the energy from the wheels and the FC during a braking trip from the current speed until it stops. Therefore, the higher $S O E$ reference of the strategy is:

$$
S O E_{h i}(k)=1-\frac{\left(E_{b r}(k)+E_{F C}^{b r}(k) \eta_{B O}\right) \eta_{B B} \eta_{S C}}{E_{S C, 0}} .
$$

So far, the expressions to compute $S O E_{\text {low }}$ and $S O E_{h i}$ were deduced. These expressions, in addition to the vehicle parameters, include the current speed and the current power flow in the FC. Accordingly, $S O E_{\text {low }}$ and $S O E_{h i}$ are adapted during runtime. These limits have a different meaning to $S O E_{\min }$ and $S O C_{\max }$ : the last ones provide the operation limits of the SC (see Eq. 4), while $S O E_{l o w}$ and $S O E_{h i}$ provide information to the proposed strategy to compute the power required from the FC. 


\subsection{Fuel cell power reference}

Once the $S O E$ limits were computed, the current state of the propulsion system is classified into one of the three modes:

$$
\begin{cases}\text { Overcharged, } & \text { if } S O E(k)>S O E_{h i}(k), \\ \text { Charged, } & \text { if } S O E_{\text {low }}(k) \leq S O E(k) \leq S O E_{h i}(k), \\ \text { Discharged, } & \text { if } S O E(k)<S O E_{\text {low }}(k) .\end{cases}
$$

Then, according to the current mode, the FC power reference is computed as follows:

$$
u_{F C}(k)= \begin{cases}0, & \text { if Overcharged, } \\ \min \left\{\max \left\{P_{c h g}^{\text {low }} ; \frac{P_{w h}(k)}{\eta_{F C}, w h}\right\} ; P_{c h g}^{h i}\right\}, & \text { if Charged, } \\ \max \left\{\frac{P_{w h}(k)}{\eta_{F C, w h}} ; P_{d i s}\right\}, & \text { if Discharged, }\end{cases}
$$

where $P_{c h g}^{l o w}, P_{c h g}^{h i}$ and $P_{d i s}$ are adjustable parameters, and $\eta_{F C, w h}$ is the efficiency of the electrical path from the FC to the wheels $\left(\eta_{F C, w h}=\eta_{B O} \eta_{E M} \eta_{D F}\right)$. In Overcharged mode, setting FC power reference equal to zero aims to avoid the $S O E$ increment. Then, in Charged mode, the objective is to remain in this mode, and therefore, a tracking of the power demanded is intended by setting the FC power reference equal to $P_{w h}(k) / \eta_{F C, w h}$. In addition, in this mode, the power reference is bounded by $P_{c h g}^{l o w}$ and $P_{c h g}^{h i}$ to avoid operating the FC at low efficiency. Finally, in Discharged mode, a tracking of the power demanded is intended, including a lower bounded, which aims to increase the $S O E$.

So far, the FC power reference was determined in order to: first, maintain the $S O E$ between $S O E_{h i}$ and $S O E_{\text {low }}$; and second, operate the FC at high efficiency. Before using this value as a power reference to the FC, it must be bounded to satisfy the multiple constraints of the propulsion system. The maximum and minimum FC power that satisfy the constraints, namely $u_{F C}^{\max }(\mathrm{k})$ and $u_{F C}^{\min }(\mathrm{k})$, can be obtained by means of (8)-(12). Notice that these values depend on: the previous state of power in the FC, the state of energy of the SC and the power demand at the wheels. Finally, the power assigned to the FC results:

$$
P_{F C}(k)=\max \left\{\min \left\{u_{F C}(k) ; u_{F C}^{\max }(k)\right\} ; u_{F C}^{\min }(k)\right\}
$$




\section{Simulation results}

The performance of the proposed strategy is evaluated under real driving conditions in two stages: first, by simulation, then, through experimental tests (Section 5). The results are compared with those obtained with the ECMS and with the optimal strategy obtained by using Dynamic Programming. The case study is described below.

\subsection{Case study}

The FCHV corresponds to a city bus. The sizing of FC and SC was addressed following the guidelines reported by [14]. Basically, the FC has power enough to maintain a constant speed of $60 \mathrm{~km} \mathrm{~h}^{-1}$ (without using the SC). With this sizing, the maximum power of the FC results significantly higher than the average power consumed by the bus during the cycles, while the size of the SC is a trade-off decision between fuel economy and SC costs. The parameters of FCHV are listed in Table 2.

In this work, two urban driving cycles are used to evaluate the performance of the strategies. The first one is the standard speed profile Manhattan Bus Cycle (MBC) [33], while the second one corresponds to a cycle of buses in the city of Buenos Aires, namely Buenos Aires Bus Cycle $(\mathrm{BABC})^{1}$ [12]. Table 3 summarizes the main properties of the driving cycles, while the speed profiles are shown below.

\subsection{Adjustment of the strategies and performance indicators}

Both strategies, EBES and ECMS, require the adjustment of some parameters. In order to realize a fair comparison, they must be properly tuned. In this work, a parametric sweep is used to determine the optimal tuning. The procedure consists in evaluating repeatedly the performance of the strategy under the same driving conditions varying the adjustable parameters in order to cover all the feasible possibilities. In this case, the driving cycle chosen is MBC. Moreover, to reduce the simulation time, only the parameters with high sensitivity are included in the parametric sweep. In the case of EBES the parameters varied are $v_{\text {max }}, P_{c h g}^{l o w}$, $P_{c h g}^{h i}$ and $P_{d i s}$, while $a_{p r}$ and $a_{b r}$ remain constant equal to 0.8 and $-1.1 \mathrm{~m} \mathrm{~s}^{-2}$, respectively. On the other hand, for the strategy ECMS, the parameters with higher sensitivity are the equivalence factor for discharge $\left(s_{d i s}\right)$; the equivalence factor for charge $\left(s_{c h g}\right)$; the time horizon $\left(t_{h}\right)$; and the reference of state of energy in the $\mathrm{SC},\left(S O E_{r e f}\right)$. More details about these parameters are found in [10]. For this strategy, many procedures to adjust the equivalence factors are

\footnotetext{
${ }^{1}$ It was created and provided by ITBA, Instituto Tecnológico de Buenos Aires.
} 
Table 2: FCHV parameters: chassis, EM, differential and electronic converters are from Autonomy ${ }^{\mathrm{TM}}[32]$; FC efficiencies from [31]; and SC from [9].

\begin{tabular}{|c|c|c|c|}
\hline Description & Parameter & Value & Unit \\
\hline Cargo mass & $m_{\text {cargo }}$ & 2400 & $k g$ \\
\hline Chassis mass & $m_{c h}$ & 11250 & $k g$ \\
\hline Frontal area & $A_{f}$ & 8.06 & $m^{2}$ \\
\hline Drag coefficient & $C_{x}$ & 0.65 & - \\
\hline \multirow{2}{*}{ Rolling coefficient } & $r_{0}$ & 0.008 & - \\
\hline & $r_{1}$ & 0.00012 & $s m^{-1}$ \\
\hline Wheel radius & $R_{w h}$ & 0.51 & $m$ \\
\hline Differential, ratio & $i_{D F}$ & 12.3 & - \\
\hline Differential, Effic. & $\eta_{D F}$ & 0.95 & - \\
\hline EM, Power max. & $P_{E M}^{\max }$ & 100 & $k W$ \\
\hline EM, Torque max. & $T_{E M}^{\max }$ & 1380 & $N m$ \\
\hline EM, Effic. & $\eta_{E M}$ & 0.88 & - \\
\hline FC, Power max. & $P_{F C}^{\max }$ & 48 & $k W$ \\
\hline FC, Power rise. max. & $\Delta P_{F C}^{\max }$ & 4.8 & $k W s^{-1}$ \\
\hline FC, Power fall. max. & $\Delta P_{F C}^{\min }$ & -4.8 & $k W s^{-1}$ \\
\hline FC, Max. efficiency & - & 52 & $\%$ \\
\hline FC, Eff. at max power & - & 40 & $\%$ \\
\hline Boost, Power max. & $P_{B O}^{\max }$ & 50 & $k W$ \\
\hline Boost, Effic. & $\eta_{B O}$ & 0.95 & - \\
\hline $\mathrm{SC}$, cells in series & $N_{\text {ser }}^{\text {cell }}$ & 130 & - \\
\hline $\mathrm{SC}$, branches in parallel & $N_{p a r}^{b r a n c h}$ & 2 & - \\
\hline $\mathrm{SC}$, cell rated capacity & $C_{S C}^{c e l l}$ & 2700 & $F$ \\
\hline $\mathrm{SC}$, cell resistance & $R_{S C}^{c e l l}$ & 0.001 & $\Omega$ \\
\hline SC, cell nominal voltage & $U_{S C}^{c e l l}$ & 2.5 & $V$ \\
\hline $\mathrm{SC}$, current max. & $I_{S C}^{\max }$ & 350 & $A$ \\
\hline $\mathrm{SC}, \mathrm{SOE} \min$. & $S O E_{\min }$ & 0.25 & - \\
\hline $\mathrm{SC}, \mathrm{SOE} \max$. & $S O E_{\max }$ & 1 & - \\
\hline Buck/Boost, Power max. & $P_{B B}^{\max }$ & 75 & $k W$ \\
\hline Buck/Boost, Effic. & $\eta_{B B}$ & 0.95 & - \\
\hline
\end{tabular}


Table 3: Properties of the driving cycles.

\begin{tabular}{lcc}
\hline Property & MBC & BABC \\
\hline Max. speed $\left[\mathrm{m} \mathrm{s}^{-1}\right]$ & 11.24 & 15.6 \\
Average speed $\left[\mathrm{m} \mathrm{s}^{-1}\right]$ & 4.74 & 3.85 \\
Max. acceleration $\left[m \mathrm{~s}^{-2}\right]$ & 2.04 & 1.54 \\
Max. desaccel. $\left[\mathrm{m} \mathrm{s}^{-2}\right]$ & -2.49 & -2.16 \\
Average accel. $\left[\mathrm{m} \mathrm{s}^{-2}\right]$ & 0.54 & 0.41 \\
Average desaccel. $\left[m \mathrm{~s}^{-2}\right]$ & -0.66 & -0.42 \\
\hline
\end{tabular}

reported in the literature $[10,19]$. However, the parametric sweep was adopted in this work to guarantee that the optimum parameters are found. Table 4 summarizes the parameters used in the parametric sweep for both strategies.

Table 4: Parameters of the parametric sweep

\begin{tabular}{ccccc}
\hline Strategy & Parameter & Min. & Max. & Step \\
\hline \multirow{4}{*}{ EBES } & $v_{\max }\left[\mathrm{m} \mathrm{s}^{-1}\right]$ & 10 & 12 & 1 \\
& $P_{c h g}^{\text {low }}[k W]$ & 10 & 25 & 2.5 \\
& $P_{c h g}^{h i}[k W]$ & 20 & 40 & 2.5 \\
& $P_{\text {dis }}[k W]$ & 5 & 55 & 5 \\
\hline \multirow{4}{*}{ ECMS } & $s_{\text {dis }}[-]$ & 1.95 & 2.45 & 0.05 \\
& $s_{c h g}[-]$ & 1.6 & 1.9 & 0.05 \\
& $t_{h}[s]$ & 8 & 13 & 1 \\
& $S O E_{\text {ref }}[\%]$ & 75 & 95 & 10 \\
\hline
\end{tabular}

As mentioned before, in the case of propulsion system with active constraints, the performance of the EMS influences, not only the fuel economy, but also the fulfillment of the driver's power requirements. Accordingly, the optimal set of parameters is the one that minimizes the fuel consumption and maximizes the power compliance at the same time. As it will be shown later, the optimization of each one of these objectives leads to different sets of parameters, and consequently the best solution results in a trade-off. The indicators used to measure such objectives are: hydrogen consumption, expressed in kilograms of $\mathrm{H}_{2}$ each $100 \mathrm{~km}\left(\mathrm{kgH}_{2}(100 \mathrm{~km})^{-1}\right)$, and degree of non-compliance $(D o N C)$ regarding the power required at the wheels. DoNC accounts for the non-fulfillment of the positive power demanded at the wheels. It is computed 
as follows:

$$
\operatorname{DoNC}[\%]=\left(1-\frac{\sum_{k=1}^{N} P_{w h}^{+}(k)}{\sum_{k=1}^{N} P_{w h}^{r e q+}(k)}\right) \times 100,
$$

where the superscript ' + ' means that only positive powers are included in the sum. With this definition, a $D o N C=0 \%$ means that the power required was fulfilled throughout the cycle, i.e. full compliance of the speed required. Another useful measurement to analyze the performance of the strategies is the amount of energy recovered from braking. In this case a new indicator, named degree of recovered energy $(D o R E)$, is defined:

$$
\operatorname{DoRE}[\%]=\frac{\sum_{k=1}^{N} P_{w h}^{-}(k)}{\sum_{k=1}^{N} P_{w h}^{r e q-}(k)} \times 100,
$$

where the superscript '-' means that only negative powers are included in the sum. With this definition, a DoRE $=100 \%$ means that the friction brakes are not used, and all the energy from braking was recovered in the SC. These indicators (DoRE and DoNC) were introduced in a previous work [14], with a slight variation in their definition, but with the same meaning.

Regarding the fuel consumption, to make a fair comparison, the difference between the initial $S O E$ and the $S O E$ at the end of the cycle is compensated by adding (or subtracting) an amount of $\mathrm{H}_{2}$ to the $\mathrm{H}_{2}$ consumed. Such compensation was made by using two equivalence factors computed from the efficiency of the components of the propulsion system, as explained in [19]. Accordingly, when the final $S O E$ is lower than the initial $S O E$, the equivalence factor is equal to 1.96 , while if the final $S O E$ is higher than the initial one, the equivalence factor used is 1.59 .

Concerning the optimal strategy, Dynamic Programming was implemented using $x_{F C}$ and $S O E$ as state variables, $P_{F C}$ as control input, and the $\mathrm{H}_{2}$ consumption as cost function. A vectorized implementation has been adopted according to guidelines from [34]. In the next section, the performance obtained with the different strategies are compared.

\subsection{Results}

For a better understanding of the proposed strategy, Fig. 5-(a) shows a segment of simulations using EBES where the three modes of the strategy appear. In this figure it can also be observed that the required speed was not achieved around $t=430 \mathrm{~s}$ and $t=490 \mathrm{~s}$.

Now, the results obtained from the parametric study are presented according to the performance in terms of fuel consumption and $\operatorname{DoNC}$. Note that we deal with a two objective problem, in which both the fuel consumption and the DoNC are minimized. The results are shown in Fig. 5-(b). In this figure, the Pareto front is also included, which is the set of the 
Table 5: Performance of the strategies over MBC.

\begin{tabular}{lcccc}
\hline Strategy & $\begin{array}{c}\text { Consumption } \\
{\left[\mathrm{kgH}_{2}(100 \mathrm{~km})^{-1}\right]}\end{array}$ & $\begin{array}{c}\text { Difference in } \\
\text { consumption } \\
{[\%]}\end{array}$ & $\begin{array}{c}\text { DoNC } \\
{[\%]}\end{array}$ & $\begin{array}{c}\text { DoRE } \\
{[\%]}\end{array}$ \\
\hline EBES & 6.34 & 0 & 3.65 & 83.4 \\
ECMS & 6.47 & +2.1 & 4.55 & 82.5 \\
Optimal strategy & 6.19 & -2.4 & 1.73 & 84.5 \\
\hline
\end{tabular}

Pareto-optimal points for each strategy [35]. In this work, a point is considered Pareto-optimal if no other point exists with lower $D o N C$ and lower Consumption at a time.

First, it can be observed that the proposed strategy presents a lower dispersion both in fuel consumption and in $D o N C$, compared to the ECMS. It means that in the case of a non-optimal adjustment of its parameters, EBES presents a lower loss of performance, which is desirable. Then, the lower consumption is obtained with the EBES, which is around $6.34 \mathrm{kgH}_{2}(100 \mathrm{~km})^{-1}$, while the $\mathrm{DoNC}$ is $3.6 \%$. The minimum $\mathrm{DoNC}$ is similar in both strategies, around $3.3 \%$. However, in the case of ECMS, the consumption increases notably at lower values of DoNC.

Now, a single set of parameters is chosen for each strategy. It is reasonable to choose a set of parameters corresponding to a point in the middle of the Pareto front for each strategy, which provides a trade-off solution between fuel economy and power compliance. Hence, the parameters of the EBES finally adopted are $v_{\max }=12 \mathrm{~ms}^{-1}, P_{c h g}^{\text {low }}=15 \mathrm{~kW}, P_{c h g}^{\text {hi }}=30 \mathrm{~kW}$, and $P_{d i s}=15 \mathrm{~kW}$; while for the ECMC the parameters are $s_{d i s}=2.05, s_{c h g}=1.7, t_{h}=11 \mathrm{~s}$, and $S O E_{r e f}=0.85$. Table 5 summarizes the results obtained using these parameters on MBC. The second column shows the differences on fuel consumption with respect to EBES. In this Table, the results of the optimal strategy obtained offline via Dynamic Programming are also included. As expected the performance obtained with the optimal solution shows a lower value of $D o N C$ and an improvement of fuel economy with respect to EBES. These results are consistent with the $D o R E$, in which the optimal strategy presents the maximum percentage of energy recovered from braking.

Then, to analyze the sensitivity of the strategies against different driving cycle conditions, they are tested using the cycle BABC, keeping the parameters adjusted for MBC. Table 6 shows the result obtained. In this case, the difference on fuel consumption between the two real-time strategies is slightly lower for the ECMS. However it presents a high DoNC. In this respect, the proposed strategy is notably better than the ECMS. High values of DoNC mean a poor 
(a)
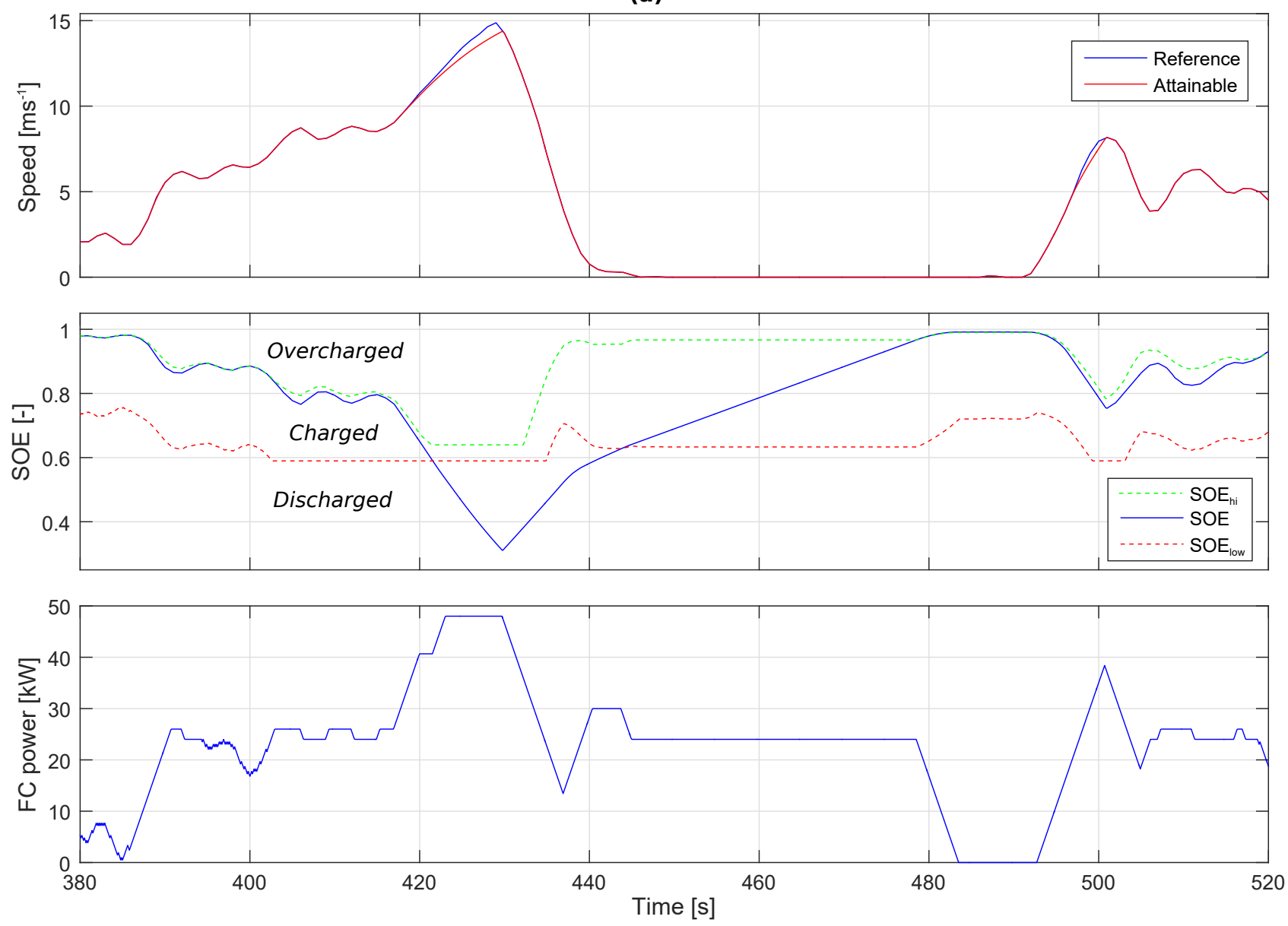

(b)

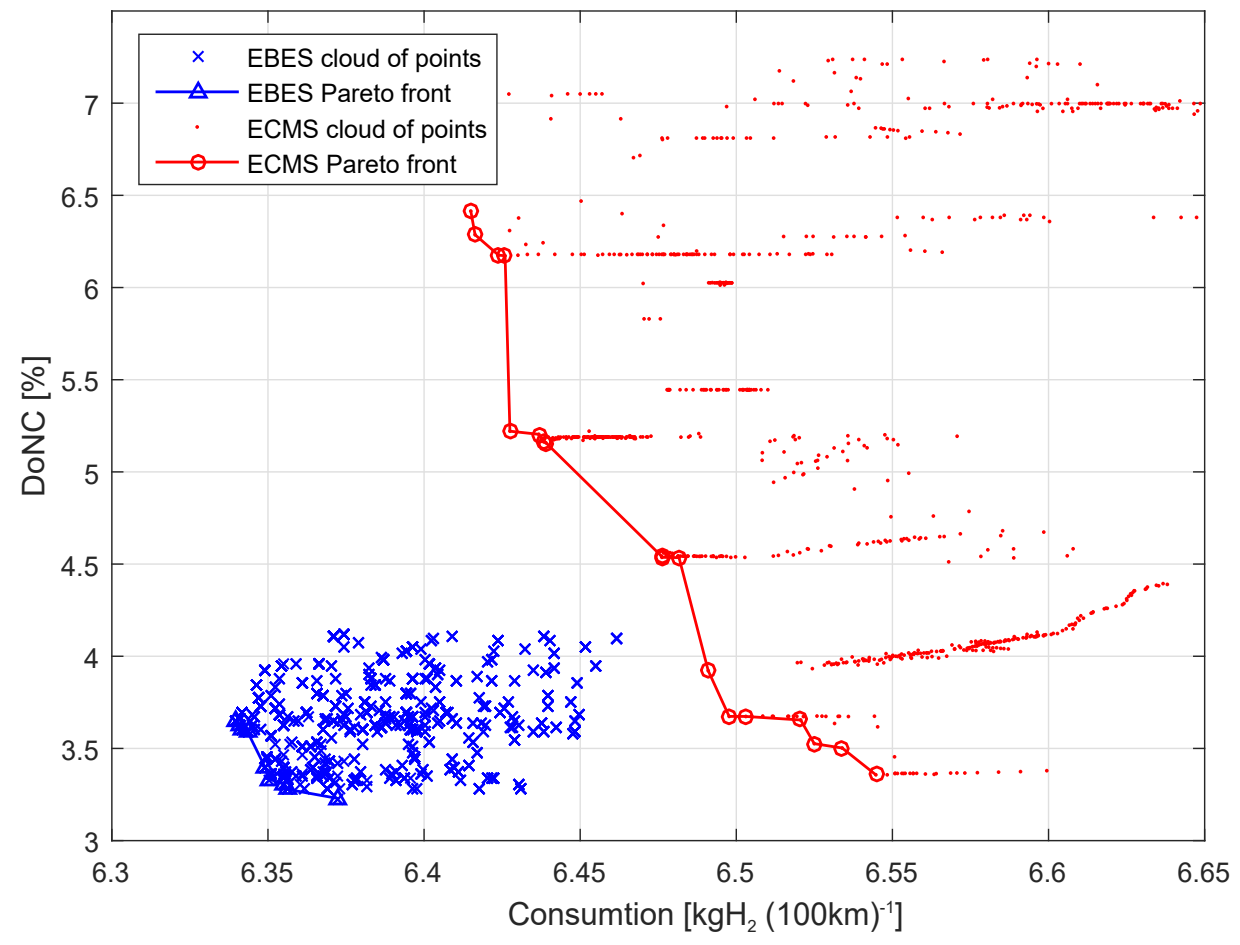

Figure 5: (a) Segment of simulation over BABC using EBES with parameters $v_{\max }=12 \mathrm{~m} \mathrm{~s}^{-1}, P_{\text {low }}^{\text {chg }}=24 \mathrm{~kW}$, $P_{h i}^{c h g}=26 \mathrm{~kW}$ and $P_{d i s}=30 \mathrm{~kW}$. (b) Performances of the strategies from a parametric sweep over MBC. 
Table 6: Performance of the strategies over BABC.

\begin{tabular}{lcccc}
\hline Strategy & $\begin{array}{c}\text { Consumption } \\
{\left[\mathrm{kgH}_{2}(100 \mathrm{~km})^{-1}\right]}\end{array}$ & $\begin{array}{c}\text { Difference in } \\
\text { consumption } \\
{[\%]}\end{array}$ & $\begin{array}{c}\text { DoNC } \\
{[\%]}\end{array}$ & $\begin{array}{c}\text { DoRE } \\
{[\%]}\end{array}$ \\
\hline EBES & 6.18 & 0 & 7.75 & 85.4 \\
ECMS & 6.14 & -0.6 & 14.3 & 86.6 \\
Optimal strategy & 5.93 & -4.8 & 7.35 & 88.2 \\
\hline
\end{tabular}

drivability, which is reflected in the loss of reference speed, as shown in the Fig. 6. Note that a lower power compliance leads to a lower consumption. Such assertion can be illustrated by a simple example. It consists on runing the simulation with the EBES, but instead of using the original BABC, the speed profile achieved by the ECMS is adopted. In this case, the EBES fully complies with the cycle, and the fuel consumption is $5.96 \mathrm{kgH}_{2}(100 \mathrm{~km})^{-1}$, i.e. $3.2 \%$ lower than ECMS. Additionally, a saving of $4.8 \%$ is achieved with the optimal solution compared to the EBES, with similar performance in terms of power compliance. The correspondence between the $\mathrm{H}_{2}$ consumption and the energy recovered is consistent.

Finally, the sensitivity of the strategies against the total mass of the vehicle is analyzed. As mentioned previously, the FCHV corresponds to a real bus used for urban transport, whereby a high variation of the cargo mass $\left(m_{\text {cargo }}\right)$ is expected due to the variation of passengers transported. A variation of $100 \%$ of $m_{\text {cargo }}$ is proposed. In the previous simulations $m_{\text {cargo }}=$ $2400 \mathrm{~kg}$ was used, which corresponds to the average of passengers, and with this value the total vehicle mass results $m=m_{c h}+m_{\text {cargo }}=13650 \mathrm{~kg}$. Now, $m_{\text {cargo }}^{\min }=0 \mathrm{~kg}$ and $m_{\text {cargo }}^{\max }=5800 \mathrm{~kg}$ are evaluated, which correspond to empty and full of passengers, respectively. This variation in the cargo mass affects the total mass in a quantity $\Delta= \pm 18 \%$ around the nominal vehicle mass $(13650 \mathrm{~kg})$. Note that the variation of this parameter was made only in the vehicle dynamic model, which affects the power required, while the strategies are computed using the same nominal value of total mass than in the previous simulations (since it would not be practical to measure the mass while the bus is running). The results obtained are summarized in Tables 7 and 8. As observed, the proposed strategy keeps the advantage of fuel economy and power compliance over ECMS, even under hight variation of cargo mass. Alternatively, the optimal strategy performs the lower fuel consumption keeping the lower level of DoNC. In Table 8, a second optimal result is included to emphasize the effect of the power compliance on the fuel consumption. This result is obtained by using the speed achieved by EBES as reference, 


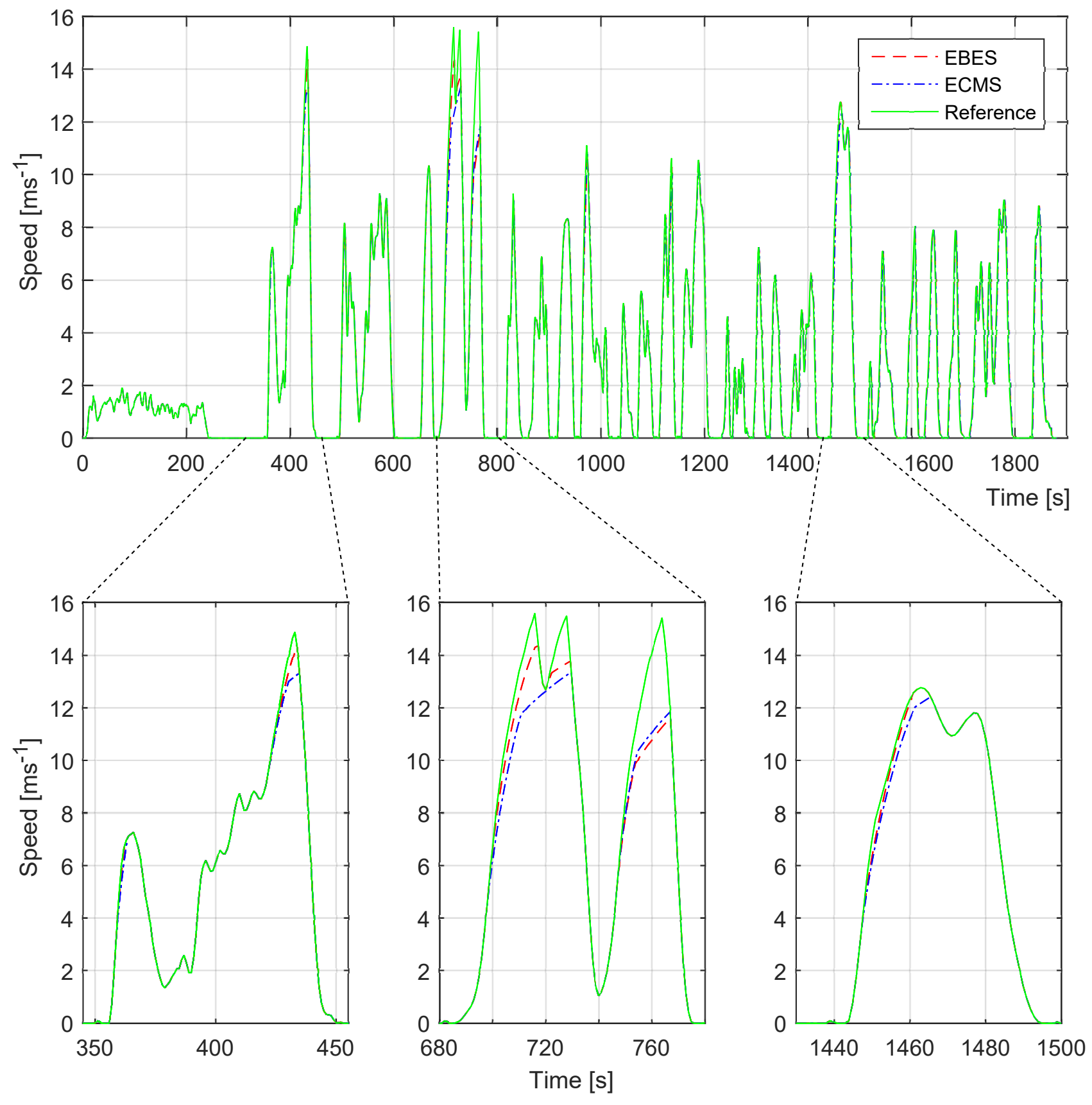

Figure 6: Loss of the speed reference in BABC.

Table 7: Performance over MBC with $m_{\text {cargo }}=0 \mathrm{~kg}$.

\begin{tabular}{lcccc}
\hline Strategy & $\begin{array}{c}\text { Consumption } \\
{\left[\mathrm{kgH}_{2}(100 \mathrm{~km})^{-1}\right]}\end{array}$ & $\begin{array}{c}\text { Difference in } \\
\text { consumption } \\
{[\%]}\end{array}$ & $\begin{array}{c}\text { DoNC } \\
{[\%]}\end{array}$ & $\begin{array}{c}\text { DoRE } \\
{[\%]}\end{array}$ \\
\hline EBES & 5.01 & 0 & 2.82 & 91.3 \\
ECMS & 5.14 & +2.6 & 6.15 & 88.9 \\
Optimal strategy & 4.82 & -3.8 & 1.22 & 92.1 \\
\hline
\end{tabular}


Table 8: Performance over MBC with $m_{\text {cargo }}=5800 \mathrm{~kg}$.

\begin{tabular}{lcccc}
\hline Strategy & $\begin{array}{c}\text { Consumption } \\
{\left[\mathrm{kgH}_{2}(100 \mathrm{~km})^{-1}\right]}\end{array}$ & $\begin{array}{c}\text { Difference in } \\
\text { consumption } \\
{[\%]}\end{array}$ & $\begin{array}{c}\text { DoNC } \\
{[\%]}\end{array}$ & $\begin{array}{c}\text { DoRE } \\
{[\%]}\end{array}$ \\
\hline EBES & 7.74 & 0 & 3.76 & 76.8 \\
ECMS & 7.91 & +2.2 & 4.42 & 76.5 \\
Optimal strategy & 7.61 & -1.7 & 1.31 & 79.2 \\
$\begin{array}{l}\text { (original cycle) } \\
\text { Optimal strategy }\end{array}$ & 7.42 & -4.2 & 0 & 81.3 \\
$($ cycle from EBES) & & & & \\
\hline
\end{tabular}

instead of the original MBC. It can be seen that the optimal solution in this case fully complies the cycle and the fuel economy decreases up to $7.42 \mathrm{kgH}_{2}(100 \mathrm{~km})^{-1}$. The results presented in the last part of this section show that the herein proposed strategy maintains a performance against variations in both driving cycle conditions and the total vehicle mass.

Despite the fact that the performance of the strategies was tested in two particular driving cycles, this practice is widely adopted in the reported literature because it offers the possibility of comparing results. On the other hand, the selected driving cycles present different properties, covering a range of accelerations and speeds (as shown in Table 3). Therefore, we can expect that the proposed strategy guaranties good result in other driving cycles with similar properties to $\mathrm{MBC}$ or $\mathrm{BABC}$.

With the aim of consolidating the results obtained by simulations, both real-time and optimal strategies were implemented and tested in a real hybrid system. In Section 5, the experimental validation is presented. 


\section{Experimental validation}

The experimental validation was carried out in the Fuel Cell Laboratory belonging to the Institut de Robòtica i Informàtica Industrial (IRI) from the Technical University of Catalonia (UPC), in Barcelona, Spain. The objectives are to verify the feasibility of the proposed EMS and the simulation results. The station used is a hybrid testing bench that uses a FC as primary energy source and a SC as energy storage system, while the load is generated by a programmable Source/Sink.

\subsection{Description of the station}

The test station used is shown in Fig. 7-(a). It is composed by the following components: a fuel cell Nexa ${ }^{\mathrm{TM}}$ model 310-0027, type proton exchange membrane, of $26 \mathrm{VDC}, 46 \mathrm{~A}$ and $1200 \mathrm{~W}$; a supercapacitor module Maxwell ${ }^{\mathrm{TM}}$ model BMOD0165, type electrical double layer, of $165 \mathrm{~F}$ and $48 \mathrm{~V}$; a three-phase DC-DC converter Semikron ${ }^{\mathrm{TM}}$, model SKS 75F B6CI 40 V12, of 75 A and 513 VDC; a programmable Source/Sink Hcherl \& Hackl GMBH ${ }^{\mathrm{TM}}$, model NL1V80C40, of 80 VDC, $40 \mathrm{~A}$ and $3200 \mathrm{~W}$; and controller National Instruments ${ }^{\mathrm{TM}}$ model Compaq Rio 9035 which has CPU Dual-Core of $1.33 \mathrm{GHz}$ and a FPGA Xilinx Kintex-7 7K70T.

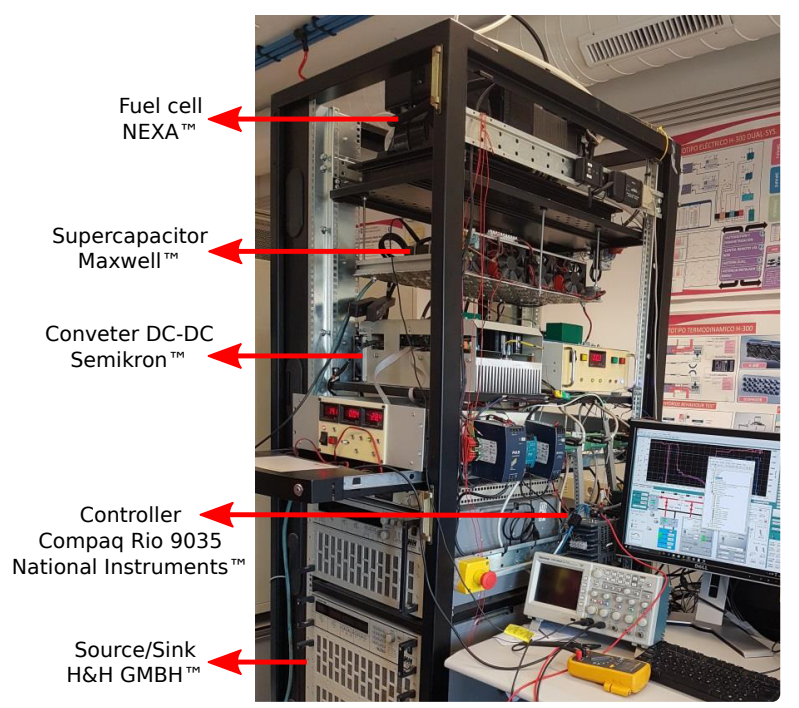

(a)

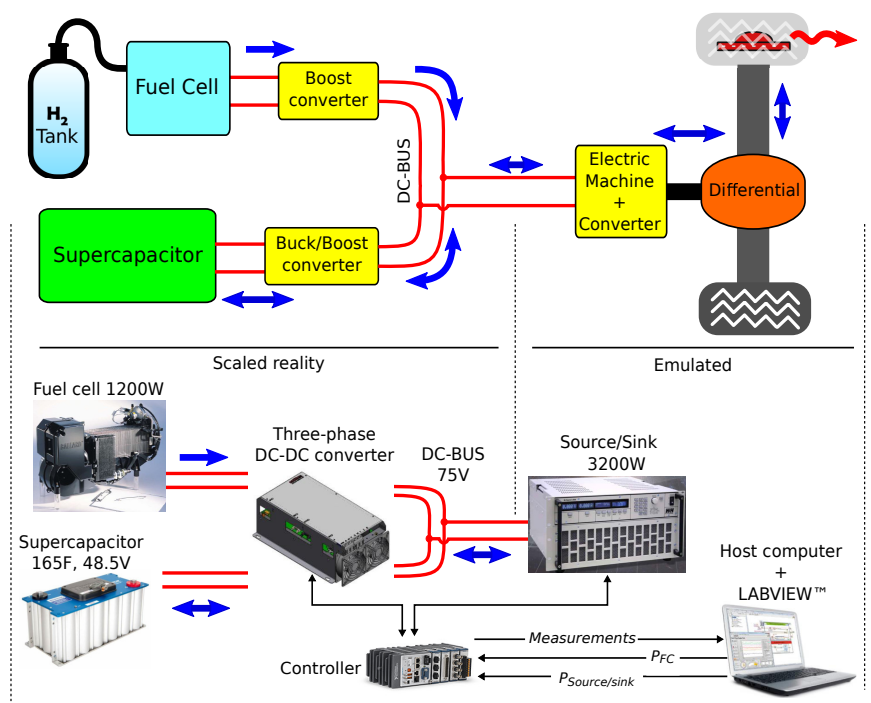

(b)

Figure 7: (a) Fuel Cell/Supercapacitor hybrid testing bench, (b) Experimental setup

Figure 7-(b) shows the adopted experimental setup. As can be seen, most of the components of the FCHV are present in the test station, with the exception of the EM and differential. Therefore, the power delivered/consumed by the EM to/from the DC-BUS is emulated using the Source/Sink. The reference power to the Source/Sink is computed from a host computer, where the driver, differential, EM and converter are simulated in LABVIEW ${ }^{\mathrm{TM}}$. The EMS is 
also executed in the host computer using a sampling time of $0.1 s$, consequently the source/sink and $\mathrm{FC}$ references are updated at this rate.

The size of the station components are significantly lower than those from the FCHV analyzed in the previous section. Thus, in order to appropriately reproduced the desired scenario, a scaling is required. The idea is that the EMS and all the emulated components use the original magnitudes, but the references to the source/sink and the FC are scaled. Similarly, the measures are inversely scaled before being introduced in the EMS and the emulated components. Note that in the experimental setup, the power delivered/received by the $\mathrm{SC}$ is controlled by a low level controller that aims to maintain constant the voltage in the DC-BUS.

\subsection{Scaling procedure}

Henceforward, the term scaled will be used to refer to the station, while the term real to refer to the real vehicle described in the previous section. As the experiments to be performed are related with the energy management, the scaling is formulated in terms of power and energy. A constant power, $P_{\text {real }}$, applied during a time interval of length $\Delta t$ produces a variation of energy:

$$
P_{\text {real }} \Delta t=\Delta E_{\text {real }}
$$

Scaling both sides of the equation leads to:

$$
P_{\text {scaled }} \Delta t=\Delta E_{\text {scaled }}
$$

Then, $k_{\text {scaling }}=P_{\text {real }} / P_{\text {scaled }}=\Delta E_{\text {real }} / \Delta E_{\text {scaled }}$ is the scale factor.

Considering the data corresponding to the station, it is possible to determine the maximum power allowed at each component of the scaled system. Similarly, considering the data from Table 2 , it is possible to obtain the maximum values of power allowed at each component of the real system. Accordingly, the minimum scale factor by power is established by the FC. Specifically, the ratio between the FC power in the real system and the FC power in the station (48kW to $1.200 \mathrm{~kW}$ ) is 40 . Regarding the energy, the energy stored in the real system, from $S O E=25 \%$ to $S O E=100 \%$, is $1648 \mathrm{~kJ}$, while in the scaled system, in the same range of $S O E$, it is $78 \mathrm{~kJ}$. This establishes that in this case, the lower bound for the $k_{\text {scaling }}$ is 21 . Finally, the scale factor adopted is 50 , so that the maximum power allowed from the FC in the experiments is $960 \mathrm{~W}$, a bit lower than its maximum power. Note that in this condition, the SC in the station is not used at full capacity, but around a $40 \%$.

Then, it is necessary to determine the range of voltage in which the SC operates in the station. The maximum voltage is $48.5 \mathrm{~V}$, which corresponds to full charge. To fit the energy 
requirement according to the scaling, two values of voltages, namely $U_{S C \text {,station }}^{\max }, U_{S C \text {,station }}^{\min }$, are found. They have to fulfill the following equation:

$$
0.5 C_{S C, \text { station }}\left(U_{S C, \text { station }}^{\max }{ }^{2}-{U_{S C, \text { station }}^{\min }}^{2}\right) k_{\text {scaling }}=E_{S C, 0}\left(S O E_{\text {max }}-S O E_{\text {min }}\right),
$$

where $C_{S C \text {,station }}$ is the capacity of the $\mathrm{SC}$ of the station, and the parameters on the right hand side correspond to the real system. Basically, this expression establishes that the maximum energy storage in the real system has to be $k_{\text {scaling }}$ times the energy storage in the scaled system. In this case, $U_{S C \text {,station }}^{\max }=46 \mathrm{~V}$ and $U_{S C, \text { station }}^{\min }=41.5 \mathrm{~V}$ were chosen. Section 5.3 presents the results obtained from the experiments.

\subsection{Experimental Results}

The two real-time strategies, i.e. EBES and ECMS, and the optimal strategy have been implemented in the test station. The strategies are tested under driving condition given by $\mathrm{MBC}$ and $\mathrm{BABC}$. Figure 8 shows a segment of the $\mathrm{MBC}$ including the evolution of the main variables obtained by simulation and experimentation. As can be seen in Fig. 8-(a), there are no appreciable differences in the speed achieved between simulation and experimentation. On the other hand, little differences can be observed in the evolution of the SOE which produces small variations on the required power to the FC. Figure 8-(c) shows the power flow in the SC. At this point, it is worth highlighting the closeness of the simulation and the experimentation despite the fact that in the simulation the power flow in the $\mathrm{SC}$ is computed from a power balance in the DC-BUS, while in the experimental setup it arises as a result of two PI controllers in cascade that attempt to maintain constant the voltage in the DC-BUS.

With regard to the $\mathrm{H}_{2}$ consumption during the experiment, it is computed from the current flow in the FC stack. Knowing that the electricity generated in the FC come from the electrochemical reaction of the hydrogen, and as the hydrogen released in purges is negligible [31], the instantaneous $\mathrm{H}_{2}$ consumption can be determined from the stack current with acceptable level of accuracy. Note that in both experimentation and simulation the difference between initial and final $S O E$ is compensated as explained previously. Regarding the stoichiometry of the supplied gases, it is controlled automatically by the FC controllers. During experiments, it was observed than the air-flow stoichiometry varies from 6 to 2 when the gross power varies from 200 to $1250 \mathrm{~W}$. Regarding the hydrogen-flow stoichiometry, it is close to 1 due to almost all the hydrogen supplied reacts, and only the hydrogen released through purges is unused.

On the other hand, it is possible to implement the optimal strategy in real-time because the driving cycle is known in advance. From Dynamic Programming method, there are two 
ways to implement the optimal strategy in the experiment. One of them is in open-loop, which means that the control input (i.e. the power setpoint to the FC) is computed offline, and during the run time it is read from a time-indexed table. This is the simplest way to implement the optimal strategy, and the value of the control input at each time depends only on the time. Such solution would work properly only when the evolution of the state variables in the experiment follow exactly the same trajectory predicted by the model. As it was shown, there are a little variation in the state variables between simulation and experimentation, which leads us to think that this solution will not be optimal. The second way to implement the optimal
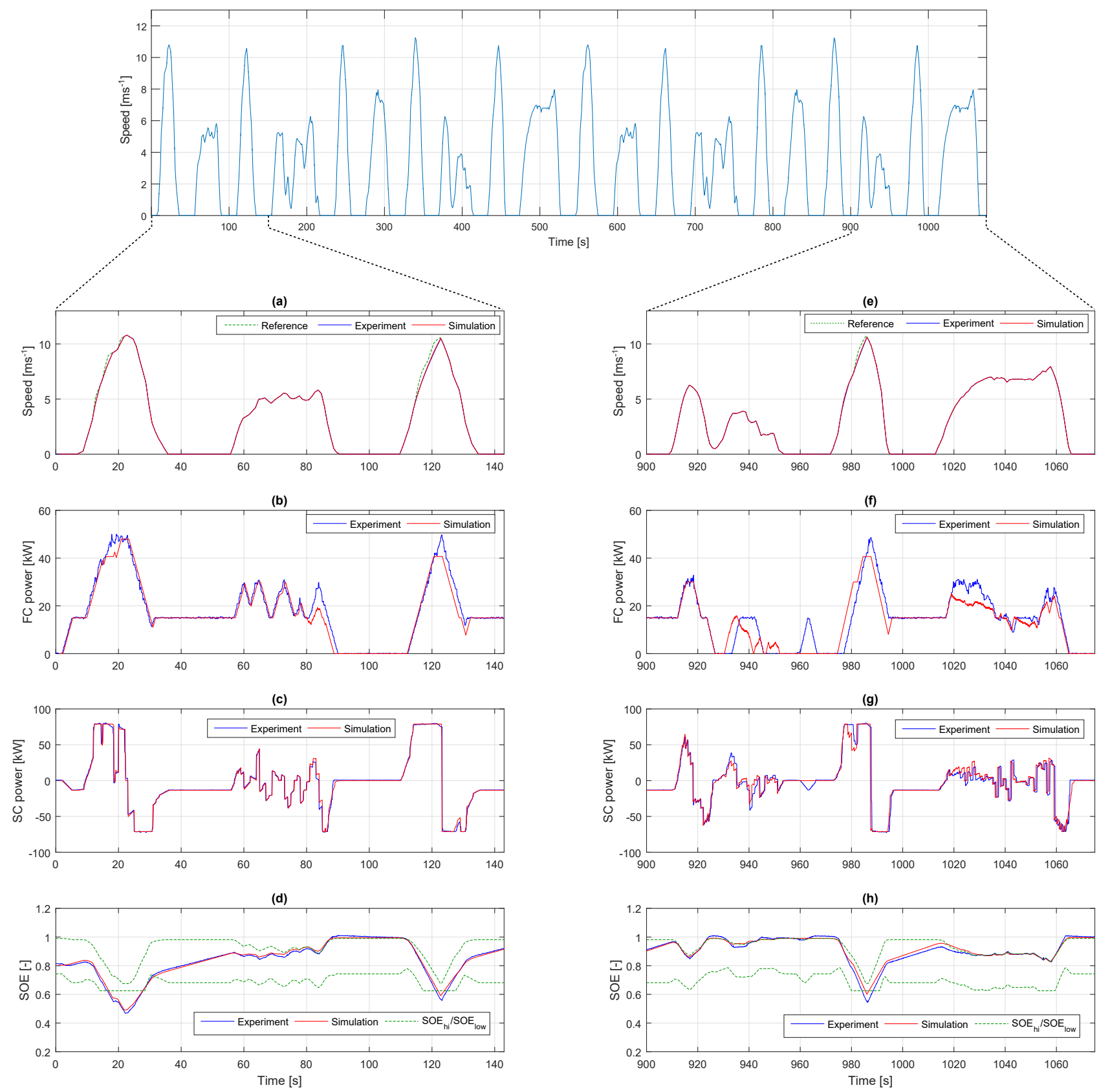

Figure 8: Experimental and simulation results over MBC using the strategy EBES 
Table 9: Performance of the strategies over MBC, experimental and simulation results

\begin{tabular}{llcc}
\hline Strategy & & $\begin{array}{c}\text { Consumption } \\
{\left[\mathrm{kgH}_{2}(100 \mathrm{~km})^{-1}\right]}\end{array}$ & $\begin{array}{c}\text { DoNC } \\
{[\%]}\end{array}$ \\
\hline \multirow{2}{*}{ EBES } & experimental & 6.62 & 5.72 \\
& simulation & 6.34 & 3.65 \\
\hline \multirow{2}{*}{ ECMS } & experimental & 6.72 & 6.57 \\
& simulation & 6.47 & 4.55 \\
\hline \multirow{2}{*}{ Optimal strategy } & experimental & 6.45 & 1.89 \\
& simulation & 6.19 & 1.73 \\
\hline
\end{tabular}

EMS is by state-feedback, from the results obtained with Dynamic Programming. In this case, the optimal control input is obtained by interpolation in a matrix indexed by state variables and time. This matrix is computed offline by Dynamic Programming using the model of the vehicle. In this way, the control input at each time depends not only on the time but also on the current values of the state variables, which are measured from the station.

Table 9 and 10 summarize the results obtained in the experiments. To make easier the comparison, the simulation results are also included. As can be seen, the fuel consumption obtained from the experiments are a little higher than from the simulations in all cases. The power compliance indicated by $D o N C$ also shows an increment in the experiments compared to the simulations. Despite such differences, the experimental results confirm the differences on favor of the EBES observed in simulation. Besides that, the implementation of the optimal strategy by state-feedback seems to provide good results in spite of the application of Dynamic Programming on a low order model of the vehicle.

There are two main factors that contribute to the differences observed between the experimental and simulation results. First, the most important in terms of fuel consumption, is the efficiency of the FC. During the simulations, the efficiency of the FC is a little higher than the efficiency achieved with the FC in the experiments. This aspect is strongly related with the stack temperature, which is internally controlled by the FC. It was observed that, due to frequent idle periods in the driving cycle, the FC operates at low temperature, which contributes to the loss of efficiency. Second, it was observed that the efficiency of the DC-DC converters in the station varies between $85 \%$ and $95 \%$ (the lower efficiency reached specially at low power), while the efficiency in simulation was considered constant equal to $95 \%$.

Summarizing, the experimental results presented in this section have shown the feasibility 
Table 10: Performance of the strategies over BABC, experimental and simulation results

\begin{tabular}{llcc}
\hline \multirow{2}{*}{ Strategy } & & $\begin{array}{c}\text { Consumption } \\
{\left[\mathrm{kgH}_{2}(100 \mathrm{~km})^{-1}\right]}\end{array}$ & $\begin{array}{c}\text { DoNC } \\
{[\%]}\end{array}$ \\
\hline \multirow{2}{*}{ EBES } & experimental & 6.37 & 9.42 \\
& simulation & 6.18 & 7.75 \\
\hline \multirow{2}{*}{ ECMS } & experimental & 6.36 & 17.2 \\
& simulation & 6.14 & 14.3 \\
\hline \multirow{2}{*}{ Optimal strategy } & experimental & 6.19 & 9.96 \\
& simulation & 5.93 & 7.35 \\
\hline
\end{tabular}

of implementation of the proposed strategy, the closeness between the simulation and the experimental results, and the improvements achieved with the EBES against the ECMS. 


\section{Conclusions}

In this work, a new EMS for a FCHV based on the prediction of the energy demand was presented. The challenge in this kind of platforms is associated with the state-dependent constraints, often activated in operation, which affects sensibly its performance. The proposed strategy was tested by simulation and experimentally under real driving conditions, and the results were compared with two references: the widely reported ECMS and the optimal strategy obtained offline by Dynamic Programming.

The proposed strategy shows improvements in fuel economy and drivability compared to ECMS. The results presented also show that the fuel economy is directly associated to the energy dissipated at the friction brakes, i.e. the amount of energy that could not be stored in SC because of active constraints. This explains that the ECMS, that basically solves a local optimization problem without forecasts about near future, presents mainly lower levels of power compliance, and also the highest $\mathrm{H}_{2}$ consumption. On the contrary, the strategy proposed herein prevents active constraint situations by using trip energy estimations and, therefore, increases the power compliance and reduces the fuel consumption. Simulations against variation in driving conditions and vehicle mass showed that the proposed strategy keeps the advantages over the ECMS. Regarding the computational burden to compute the EMS, the EBES performs the simple mathematical operations presented in Section 3.2, which makes this strategy suitable for real-time application. Finally, the experiments confirmed the feasibility of the proposed strategy; the validity of to use a quasistatic model for simulations; and the advantages of the EBES over the ECMS.

Nowadays, where FCHVs are trying to gain a place in the automotive market, is crucial to reduce the cost of these platforms by reducing the size of its components. As a consequence, powertrain components are operated frequently close to the limits (e.g. maximum power, power rates, $S O E$ ), affecting the performance of the vehicle. In this scenario, the results presented in this work make the proposed strategy an interesting option to manage the energy in this kind of platform. Despite the improvements achieved, the comparison with the optimal solution shows that real-time strategies still have a room for improvement in terms of power compliance and fuel economy. 


\section{Acknowledgements}

This work was supported by Bec.Ar, Programa de Becas de Formación en el Exterior en Ciencia y Tecnología of Ministerio de Modernización of Argentina; by the project MINECO/FEDER of the Ministerio de Educación de España [grant number DPI2015-69286-C3-2-R]; and by AGAUR agency of the Generalitat de Catalunya [grant number 2014 SGR 267]. The first author also wishes to thank CONICET, Consejo Nacional de Investigaciones Científicas y Técnicas for its financial support through the PhD fellowship; and Escuela de Ingeniería Mecánica of Universidad Nacional de Rosario (EIM-FCEIA-UNR) for providing the workspace. 


\section{References}

[1] N. Sulaiman, M. Hannan, A. Mohamed, E. Majlan, W. W. Daud, A review on energy management system for fuel cell hybrid electric vehicle: Issues and challenges, Renewable and Sustainable Energy Reviews 52 (2015) 802-814.

[2] S. Strahl, N. Gasamans, J. Llorca, A. Husar, Experimental analysis of a degraded opencathode pem fuel cell stack, International journal of hydrogen energy 39 (2014) 5378-5387.

[3] R. Borup, J. Meyers, B. Pivovar, Y. S. Kim, R. Mukundan, N. Garland, D. Myers, M. Wilson, F. Garzon, D. Wood, et al., Scientific aspects of polymer electrolyte fuel cell durability and degradation, Chemical reviews 107 (2007) 3904-3951.

[4] M. Uchimura, S. S. Kocha, The impact of cycle profile on PEMFC durability, ECS Transactions 11 (2007) 1215-1226.

[5] A123-Systems, Datasheet Specs A123 Lithium Ion Prismatic Cell AMP20M1HD-A, 2016. Available from www.a123systems.com/prismatic-cell-amp20.htm.

[6] Enerdel, Datasheet Specs Enerdel Moxie Prismatic Cell CE175-360, 2016. Available from www.enerdel.com/ce175-360-moxie-prismatic-cell/.

[7] B. G. Pollet, I. Staffell, J. L. Shang, Current status of hybrid, battery and fuel cell electric vehicles: From electrochemistry to market prospects, Electrochimica Acta 84 (2012) 235249.

[8] S. J. Moura, J. B. Siegel, D. J. Siegel, H. K. Fathy, A. G. Stefanopoulou, Education on vehicle electrification: battery systems, fuel cells, and hydrogen, in: 2010 IEEE Vehicle Power and Propulsion Conference, IEEE, pp. 1-6.

[9] Maxwel, Datasheet Specs Maxwel Electric Double Layer Capacitor Series PC2500, 2016. Available from www.datasheets360.com/pdf/8947558111616779586.

[10] P. Rodatz, G. Paganelli, A. Sciarretta, L. Guzzella, Optimal power management of an experimental fuel cell/supercapacitor-powered hybrid vehicle, Control Engineering Practice 13 (2005) 41-53.

[11] P. Rodatz, L. Guzzella, L. Pellizzari, System design and supervisory controller development for a fuel-cell vehicle, in: Proc., 1st International Federation of Automatic Control Conference on Mechatronic Systems, volume 1, pp. 18-20. 
[12] M. G. Carignano, R. Adorno, N. Van Dijk, N. Nieberding, N. M. Nigro, P. Orbaiz, Assessment of energy management strategies for a hybrid electric bus, in: International Conference on Engineering Optimization, EngOpt 2016. Iguassu Falls, Brazil.

[13] M. G. Carignano, D. Feroldi, N. M. Nigro, R. Costa-Castelló, MPC como estrategia de gestión energética para un vehículo híbrido eléctrico, in: XXXVII Jornadas de Automtica, Comité Espaol de Automática (CEA-IFAC), 2016, pp. 316-323.

[14] D. Feroldi, M. Carignano, Sizing for fuel cell/supercapacitor hybrid vehicles based on stochastic driving cycles, Applied Energy 183 (2016) 645-658.

[15] L. V. Pérez, C. H. De Angelo, V. L. Pereyra, Determination of the equivalent consumption in hybrid electric vehicles in the state-constrained case, Oil \& Gas Science and TechnologyRevue dIFP Energies nouvelles 71 (2016) 30.

[16] S. F. Tie, C. W. Tan, A review of energy sources and energy management system in electric vehicles, Renewable and Sustainable Energy Reviews 20 (2013) 82-102.

[17] K. Ç. Bayindir, M. A. Gözüküçük, A. Teke, A comprehensive overview of hybrid electric vehicle: Powertrain configurations, powertrain control techniques and electronic control units, Energy Conversion and Management 52 (2011) 1305-1313.

[18] D. Feroldi, M. Serra, J. Riera, Energy management strategies based on efficiency map for fuel cell hybrid vehicles, Journal of Power Sources 190 (2009) 387-401.

[19] L. Guzzella, A. Sciarretta, et al., Vehicle propulsion systems, volume 1, Springer, 2007.

[20] J. Luna, E. Usai, A. Husar, M. Serra, Nonlinear observation in fuel cell systems: A comparison between disturbance estimation and high-order sliding-mode techniques, International Journal of Hydrogen Energy (2016).

[21] J. Luna, S. Jemei, N. Yousfi-Steiner, A. Husar, M. Serra, D. Hissel, Nonlinear predictive control for durability enhancement and efficiency improvement in a fuel cell power system, Journal of Power Sources 328 (2016) 250-261.

[22] M. Uzunoglu, M. Alam, Modeling and analysis of an FC/UC hybrid vehicular power system using a novel-wavelet-based load sharing algorithm, IEEE Transactions on Energy Conversion 23 (2008) 263-272. 
[23] Z. Yu, D. Zinger, A. Bose, An innovative optimal power allocation strategy for fuel cell, battery and supercapacitor hybrid electric vehicle, Journal of Power Sources 196 (2011) 2351-2359.

[24] V. Paladini, T. Donateo, A. De Risi, D. Laforgia, Super-capacitors fuel-cell hybrid electric vehicle optimization and control strategy development, Energy Conversion and Management 48 (2007) 3001-3008.

[25] S. Kelouwani, K. Agbossou, Y. Dubé, L. Boulon, Fuel cell plug-in hybrid electric vehicle anticipatory and real-time blended-mode energy management for battery life preservation, Journal of Power Sources 221 (2013) 406-418.

[26] F. Soriano Alfonso, et al., A study of hybrid powertrains and predictive algorithms applied to energy management in refuse-collecting vehicles, Materia (s) 22 (2015) 05-2015.

[27] L. Valverde, C. Bordons, F. Rosa, Integration of fuel cell technologies in renewableenergy-based microgrids optimizing operational costs and durability, IEEE Transactions on Industrial Electronics 63 (2016) 167-177.

[28] J. S. Martinez, D. Hissel, M.-C. Pera, M. Amiet, Practical control structure and energy management of a testbed hybrid electric vehicle, IEEE Transactions on Vehicular Technology 60 (2011) 4139-4152.

[29] S. N. Motapon, L.-A. Dessaint, K. Al-Haddad, A comparative study of energy management schemes for a fuel-cell hybrid emergency power system of more-electric aircraft, IEEE Transactions on Industrial Electronics 61 (2014) 1320-1334.

[30] C.-Y. Li, G.-P. Liu, Optimal fuzzy power control and management of fuel cell/battery hybrid vehicles, Journal of power sources 192 (2009) 525-533.

[31] B. P. S. Inc., Nexa ${ }^{\text {TM }}$ Power Module User's Manual, MAN5100078, 2003. Available from http://my.fit.edu/swood/Fuel\%20Cell\%20Manual.pdf.

[32] A. Moawad, P. Balaprakash, A. Rousseau, S. Wild, Novel large scale simulation process to support dots cafe modeling system, in: Proceedings of the International Electric Vehicle Symposium and Exhibition.

[33] T. Barlow, S. Latham, I. McCrae, P. Boulter, A reference book of driving cycles for use in the measurement of road vehicle emissions, TRL Published Project Report (2009). 
[34] M. G. Carignano, N. M. Nigro, S. Junco, HEVs with reconfigurable architecture: a novel design and optimal energy management, in: Integrated Modeling and Analysis in Applied Control and Automation (IMAACA), 2016 I3M, pp. 59-67.

[35] W. Na, B. Gou, The efficient and economic design of pem fuel cell systems by multiobjective optimization, Journal of Power Sources 166 (2007) 411-418. 